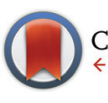

CrossMark \&lick for updates

Cite this: Polym. Chem., 2016, 7, 7002

Received 30th September 2016 Accepted 23rd October 2016

DOI: $10.1039 / c 6 p y 01709 f$

www.rsc.org/polymers

\section{Synthesis of well-defined catechol polymers for surface functionalization of magnetic nanoparticles $\uparrow$}

\author{
Qiang Zhang, ${ }^{a}$ Gabit Nurumbetov, ${ }^{\text {a }}$ Alexandre Simula, ${ }^{a}$ Chongyu Zhu, ${ }^{\text {a }}$ Muxiu Li, ${ }^{\text {a }}$ \\ Paul Wilson, ${ }^{a}$ Kristian Kempe, ${ }^{a}$ Bin Yang, ${ }^{b}$ Lei Tao ${ }^{b}$ and David M. Haddleton*a
}

In order to obtain dual-modal fluorescent magnetic nanoparticles, well-defined fluorescent functional polymers with terminal catechol groups were synthesized by single electron transfer living radical polymerization (SET-LRP) under aqueous conditions for "grafting to" modification of iron oxide nanoparticles. Acrylamide, $\mathrm{N}$-isopropylacrylamide, poly(ethylene glycol) methyl ether acrylate, 2-hydroxyethyl acrylate, glycomonomer and rhodamine B piperazine acrylamide were homo-polymerized or blockcopolymerized directly from an unprotected dopamine-functionalized initiator in an ice-water bath. The $\mathrm{Cu}$-LRP tolerated the presence of catechol groups leading to polymers with narrow molecular weight distributions $\left(M_{w} / M_{n}<1.2\right)$ and high or full conversion obtained in a few minutes. Subsequent immobilization of dopamine-terminal copolymers on an iron oxide surface were successful as demonstrated by Fourier transform infrared spectroscopy (FTIR), dynamic light scattering (DLS), transition electron microscopy (TEM) and thermogravimetric analysis (TGA), generating stable polymer-coated fluorescent magnetic nanoparticles. The nanoparticles coated with hydrophilic polymers showed no significant cytotoxicity when compared with unmodified particles and the cellular-uptake of fluorescent nanoparticles by A549 cells was very efficient, which also indicated the potential application of these advanced nano materials for bio-imaging.

\section{Introduction}

Nanoparticles decorated with biofunctional polymers have received increasing attention in the last two decades due to both their ability to simulate the endocytosis process and to their potential in medical diagnostics and treatment. ${ }^{1-3}$ Uptake of engineered nanoparticles into cells tends to be size, shape and charge-dependent. ${ }^{2,4,5}$ The properties of surface materials are also of importance for the targeted delivery of particles into specific cells, or even defined organelles. ${ }^{5,6}$ Immobilization of carbohydrates, especially glycopolymers, onto magnetic or fluorescent nanoparticles has previously been exploited for pathogen detection and cell imaging. ${ }^{7,8}$

Dopamine has been frequently used as a robust anchor to immobilize functional molecules, e.g. metalated complexes, monosaccharides as well as functional polymers to the surface

\footnotetext{
${ }^{a}$ Department of Chemistry, University of Warwick, CV4 7AL Coventry, UK.

E-mail: D.M.Haddleton@warwick.ac.uk

${ }^{b}$ The Key Laboratory of Bioorganic Phosphorus Chemistry \& Chemical Biology (Ministry of Education), Department of Chemistry, Tsinghua University, Beijing 100084, P. R. China

$\dagger$ Electronic supplementary information (ESI) available. See DOI: 10.1039/ c6py01709f
}

of metal oxide materials, including iron oxide, titanium oxide and aluminum oxide etc. ${ }^{4,9-14}$ Controlled radical polymerizations initiated or mediated by dopamine-functionalized initiators or chain transfer agents (CTA), typically transition metal mediated living radical polymerization (TMM-LRP) and reversible addition-fragmentation chain transfer (RAFT) polymerization, have shown promising applications in obtaining well-defined catechol polymers. RAFT polymerization shows excellent tolerance to catechol groups and various welldefined polymers could be successfully synthesized from dopamine-functionalized CTA. ${ }^{15-18}$ These polymers had relatively narrow molecular weight distribution $\left(M_{\mathrm{w}} / M_{\mathrm{n}}<1.20\right)$ and no significant radical coupling side reactions were observed, which indicated that the RAFT system could effectively control the concentration and present time of active radicals during polymerization and the effect of radical scavenge caused by catechol group to the polymerization was not obvious. ${ }^{15-18}$ However, when using TMM-LRP to synthesize catecholcontaining polymers the interaction between catechol groups and transition metal catalysts can be problematic. Any chelates formed by catechol groups and metal ions have been shown to have very high stability constants and can also be pH-dependent, typically shown as the form, break and reform of mono-, bis- or tris catechol-Fe ${ }^{3+}$ complexes, which have been used to 
induce cross-linked self-healing gels. ${ }^{19}$ Copper(II) complexes could potentially act as effective catalysts to accelerate the oxidation of catechol groups. ${ }^{20}$

In order to avoid the interference from catechol groups, protected dopamine-functionalized initiators were successfully used for atom transfer radical polymerization (ATRP) of zwitterionic monomers yet the final polymers possessed relatively broad MW distribution $\left(M_{\mathrm{w}} / M_{\mathrm{n}}=1.5-1.8\right)$, indicating the polymerization needed further optimization. ${ }^{21-23}$ Although ATRP of methacrylate monomers using unprotected dopamine-functionalized initiator could occur, no detailed polymerization kinetic plots or clear MW distribution data were reported. ${ }^{24}$ Hydrophobic polymers with terminal catechol groups have been synthesized by ATRP and single electron transfer living radical polymerization (SET-LRP) in organic solvents utilizing unprotected dopamine-functionalized initiators, which showed slow polymerization rate and low monomer conversion in high DP polymerization yet the final polymers showed relatively broad MW distribution. ${ }^{25}$ Control experiments by copper wire mediated SET-LRP using a protected initiator in toluene/alcohol mixed solvents lead to polymers with much narrower MW distribution (dispersity, $D$ ) as compared to those prepared with the protected initiator, suggesting the side reactions of catechol groups cannot be overlooked in this system. Our central hypothesis was that well defined hydrophilic polymers with terminal catechol anchors could be synthesized by our recently developed SET-LRP strategy in an aqueous solvent system. ${ }^{26,27}$

In this present work, several fluorescent (co)polymers were synthesized directly from unprotected a dopamine-functionalized initiator by SET-LRP in an aqueous solvent and were subsequently used for surface modification of iron oxide leading to dual-modal fluorescent magnetic nanoparticles. The cell uptake behaviours of these functional polymer-coated nanoparticles were studied, which also proved these particles are useful tools for efficient cellular uptake and biomedical imaging.

\section{Results and discussion}

\section{Synthesis and characterization of dopamine-terminal hydrophilic/fluorescent polymers}

Dopamine, and certain derivatives, have shown high activities in free radical scavenging thus the catechol groups are often protected when dopamine-functionalized monomers are used in free radical polymerizations. ${ }^{28,29}$ In order for successful polymerization of unprotected dopamine-functionalized monomers reactions were often performed in high-polar aprotic solvents such as $N, N$-dimethylformamide, dimethyl sulfoxide or acetonitrile, in which case the catechol groups were believed to possibly form non-covalent bonds with the solvent thus limiting the interaction of catechol with propagating radicals. ${ }^{30-32}$ Previous research has also suggested to avoid the use of protic polar solvents e.g. alcohols as in these solvents the hydrogen donating behavior of catechols to scavenge free radicals was not deduced. ${ }^{30,33}$
However, recent developments in SET-LRP have shown that SET-LRP is suitable for polymerization of many monomers under conditions that used to be thought as a challenge for ATRP; especially for the polymerization of water-soluble monomers when using water as the only solvent. ${ }^{26,34-36}$ Thus taking acrylamide (AM) as an example, reports on the successful ATRP of this hydrophilic monomer in aqueous media have been limited, which generally reflected difficult control in polymerization such as significantly differed apparent molecular weight, relatively high MW dispersities and failed chain extension reactions due to the loss of terminal groups etc. $^{27,37-43}$ It has been reported that the competitive coordination of solvent, monomer and polymer to the transition metal may cause reversible dissociation of halide ligand from the catalyst complexes, leading to often poorly controlled polymerizations. ${ }^{44,45}$ In this aqueous system, water or conjugated monomers and nitrogen-containing polymers may be also able to solvate the halide ligand or coordinate with the copper, which may cause inefficient deactivation and lead to poor control during the polymerization. ${ }^{46,47}$

However, when SET-LRP of AM was carried out in water using a prior disproportionation strategy the polymerization was rapid and very high, or even full, conversion could be obtained over minutes to hours even at ambient or subambient temperatures used to reduce the possible loss of terminal halogen groups, Table 1. Size exclusion chromatography (SEC) characterization revealed MW dispersities as low as 1.13 for the final poly(AM) albeit with relatively low DP. On increasing the DP from 80 to 320 and 640 , the $M_{\mathrm{w}} / M_{\mathrm{n}}$ increased from 1.13 to 1.24 and 1.35 with a slight reduction in the polymerization rate, Table 1, suggesting fine control during the polymerization although termination still occurred during the long-time scales.

The experimental MW $\left(M_{\mathrm{n}}\right)$ from SEC varied from the theoretically MW which is ascribed to the use of PEO-PEG molecular weight SEC calibration standards rather than narrow dispersed poly(AM) used in the aqueous SEC. However, with the increase of DP from 80 to 320 and 640, the measured $M_{\mathrm{n}}$ increased linearly, which indicated the living nature of the polymerization, Table $1 \&$ Fig. S3. $\dagger$ In order to test the chain extension ability of poly(AM), in situ addition of 2-hydroxyethyl acrylate (HEA) after high conversion polymerization of AM was successfully performed for block copolymerization. SEC revealed a significant shift of elution trace after chain extension indicating $\mathrm{MW}$ increase and the $M_{\mathrm{w}} / M_{\mathrm{n}}$ only increased from 1.14 to 1.37 , Fig. S4. $\dagger$ The ${ }^{1} \mathrm{H}$ NMR spectrum of the final polymer also confirmed the ratio of AM and HEA, Fig. S5. $\dagger$ It is hypothesized that the $\mathrm{Cu}^{0}$, rather than $\mathrm{Cu}^{\mathrm{I}}$, acts as the activator and the $\mathrm{Me}_{6}$ TREN ligand is able to strongly coordinate with the $\mathrm{Cu}^{\mathrm{II}}$, which inhibits the competitive coordination of water, $\mathrm{AM}$ and poly(AM) to the activators and deactivators, are two key factors for the successful polymerization of $\mathrm{AM}$ in water.

We were inspired by the exceptional ability of aqueous SET-LRP for the successful polymerization of monomers usually prone to result in catalyst deactivation and decided to 
Table 1 Experimental conditions and characterization data for the hydrophilic homo-polymers synthesized via aqueous SET-LRP

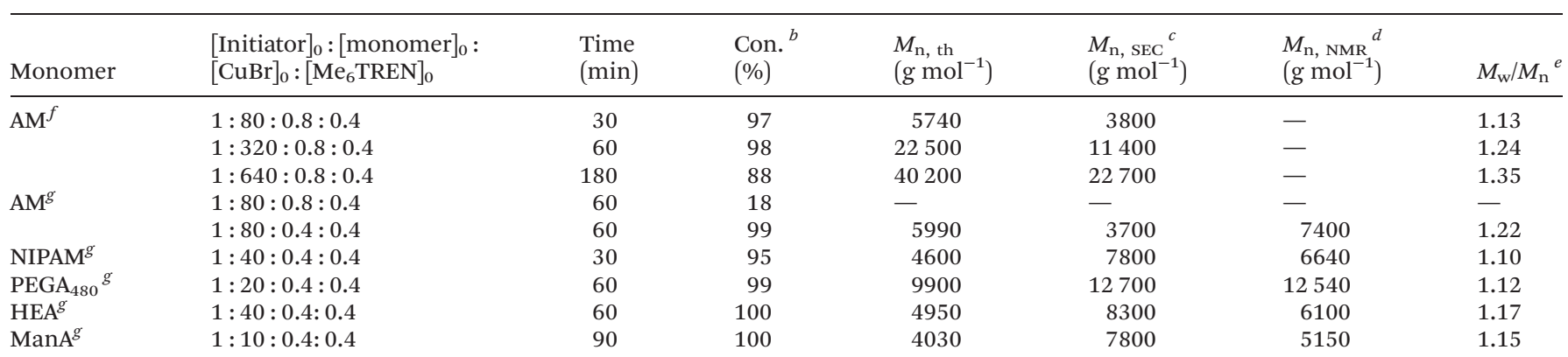

${ }^{a}$ Reaction conditions: $T=0{ }^{\circ} \mathrm{C}$ for all polymerizations; solvent, water $(2 \mathrm{~mL})$ for the disproportionation of $\mathrm{CuBr} / \mathrm{Me} \mathrm{e}_{6} \mathrm{TREN}$, water $(2 \mathrm{~mL}) / \mathrm{i}$-PrOH $(2 \mathrm{~mL})$ mixture for solubilization of monomer/initiator unless otherwise stated. ${ }^{b}$ Conversion determined by ${ }^{1} \mathrm{H}$ NMR spectroscopy. ${ }^{c}$ Numberaverage molecular weight determined by aqueous size exclusion chromatography (SEC) using PEO-PEG standards for poly(AM) and by DMF SEC using PMMA standards for poly(NIPAM), poly $\left(\mathrm{PEGA}_{480}\right)$, poly(HEA) and poly(ManA). ${ }^{d}$ Number-average molecular weight $\left(M_{\mathrm{n}}\right)$ calculated by ${ }^{1} \mathrm{H}$ NMR. ${ }^{e}$ Dispersity determined by SEC. ${ }^{f}$ Polymerization initiated by 2,3-dihydroxypropyl 2-bromo-2-methylpropanoate and pure water was used to solubilize the monomer/initiator. ${ }^{g}$ Polymerization initiated by the dopamine-functionalized initiator.

apply this for the synthesis of dopamine terminal-functionalized polymers. In one polymerization of AM from unprotected dopamine-functionalized initiator utilizing the same catalyst ratio and 2,3-dihydroxypropyl 2-bromo-2-methylpropanoate, the polymerization reached $18 \%$ after $1 \mathrm{~h}$ and SEC did not detect any significant polymer peaks, possibly due to the low MW of obtained polymers. We believe that the competitive coordination of catechol groups to the copper caused the slow polymerization. Thus the ratio of $[\mathrm{CuBr}] /\left[\mathrm{Me}_{6} \mathrm{TREN}\right]$ was decreased from $2: 1$ to $1: 1$ aiming to increase the amount of $\mathrm{Me}_{6}$ TREN to stabilize the deactivator and thus promote disproportionation. In this case, the polymerization proceeded faster with the conversion reaching $>99 \%$ in $1 \mathrm{~h}$ and the $M_{\mathrm{w}} / M_{\mathrm{n}}$ of final polymer was as low as 1.22, Fig. 1A.

${ }^{1} \mathrm{H}$ and ${ }^{13} \mathrm{C}$ NMR spectra of the final product displayed characteristic resonances at 6.6-6.9 ppm (for $H_{\mathrm{e}}, H_{\mathrm{d}}$ and $H_{\mathrm{f}}$ ), 2.5-3.5 ppm (for $H_{\mathrm{k}}$ and $H_{\mathrm{j}}$, enlarged part) and 115-145 ppm (for $C_{\mathrm{e}}, C_{\mathrm{d}}, C_{\mathrm{f}}, C_{\mathrm{g}}, C_{\mathrm{h}}$ and $C_{\mathrm{i}}$, enlarged part) respectively, Fig. 1B, which clearly showed the presence of a terminal cate- chol unit. The average MW calculated by comparing the integration of protons from the catechol groups with that from the polymer backbones was $7400 \mathrm{~g} \mathrm{~mol}^{-1}$, which was almost $20 \%$ higher than the theoretical MW. A considerable difference in experimental and theoretical MW has often been observed in TMM-LRP when using amide functional initiators, which has been attributed to possible termination at low chain length. ${ }^{48}$

In order to demonstrate the versatility of this strategy, aqueous polymerization of four additional monomers NIPAM, $\mathrm{PEGA}_{480}$, HEA and ManA were carried out using our dopamine-functionalized initiator. Detailed polymerization conditions and results of polymerization of these monomers are summarized in Table 1. Generally low DP ranging from 10 to 40 was chosen in order to confirm the presence of catechol residues in the final polymer products by NMR. All polymerizations went fast and high conversion (>95\%) was obtained in 30 to 90 minutes, Table 1.

It is noted that a significant induction period of about one hour was often observed when a dopamine-functionalized
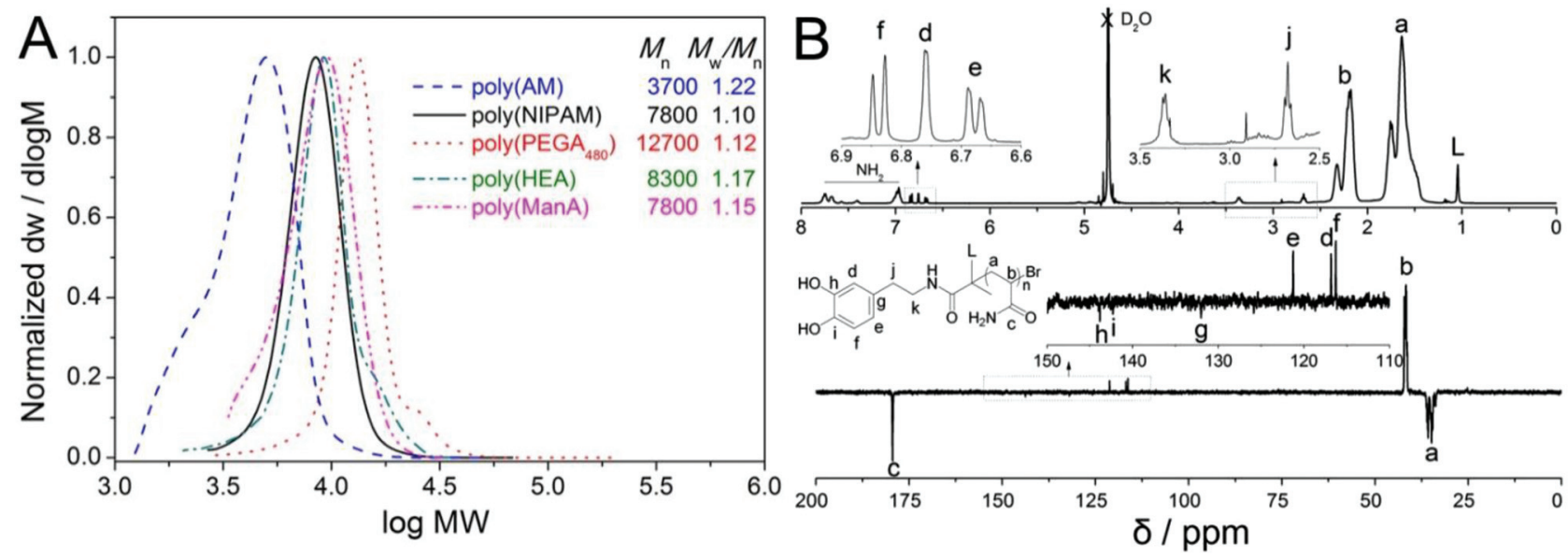

Fig. 1 Molecular weight distributions of hydrophilic homo-polymers synthesised via aqueous SET-LRP as measured by SEC (A) and ${ }^{1} \mathrm{H} \&{ }^{13} \mathrm{C}$ NMR spectra of dopamine-terminal poly(AM) (B). 
chain transfer agent was utilized in RAFT polymerization. ${ }^{16}$ However, no significant induction period was observed these current polymerizations and often polymerization proceeded so fast that samples could not be taken in time for the firstorder kinetic plots to be measured.

SEC characterization confirmed a narrow MW distribution of obtained polymers as low as 1.10 with no significant radicalradical coupling side reactions observed even after full conversion polymerization or when the reaction mixtures were left overnight, except small shoulder peaks for the poly $\left(\mathrm{PEGA}_{480}\right)$ and poly(HEA) as is often observed, Fig. 1A. ${ }^{1} \mathrm{H}$ and ${ }^{13} \mathrm{C}$ NMR characterization also confirmed the presence of catechol groups (Fig. S9-S16†) and even after dialysis and lypholization no significant oxidation of the catechol groups by oxygen in the air was observed by NMR. The average MW revealed by NMR was $\sim 20-30 \%$ higher than the theoretical values, Table 1, providing further evidence of the possible occurrence of radical coupling or disproportionation termination at the starting stage of polymerization. All these results strongly proved the successful synthesis of well-defined hydrophilic functional polymers entailed with terminal dopamine fragment.

This polymerization retains high chain end fidelity allowing for the synthesis of multi-block copolymerization at low temperatures $\left(0{ }^{\circ} \mathrm{C}\right)$ which in turn significantly reduces the rate of hydrolysis of terminal halogen groups. ${ }^{26,49}$ In order to check the chain extension ability and also to incorporate a fluorescence tag for dual-model detection, the in situ block copolymerization of a Rhodamine B acrylamide-based monomer (Rhod AM) was performed. After full monomer conversion, as monitored by the disappearance of vinyl groups by ${ }^{1} \mathrm{H}$ NMR spectra (Fig. S17 $\dagger$ ), a degassed solution of Rhod AM/TEA was directly added to the reaction for further copolymerization, Scheme 1. After chain extension reaction, SEC revealed a significant $\mathrm{MW}$ increase and the $M_{\mathrm{w}} / M_{\mathrm{n}}$ remained narrow indicating fine control during the polymerization, Fig. 2A. The ${ }^{1} \mathrm{H}$ NMR spectrum of the pink copolymer product showed typical resonances from both the terminal catechol and side Rhodamine $\mathrm{B}$ unit at 6-8 ppm, Fig. 2B. Besides the fluorescent glycopolymer, dopamine-terminal poly(HEA)- $b$-(Rhod AM) and poly(PEGA 480$)-b$-(Rhod AM) were also successfully synthesized and characterized (Fig. S18$\mathrm{S} 23 \dagger)$ for further immobilization to magnetic iron oxide particles.

In summary, well-defined dopamine-terminal fluorescent copolymers have been successfully prepared by aqueous SET-LRP, which showed dramatic tolerance to the catechol

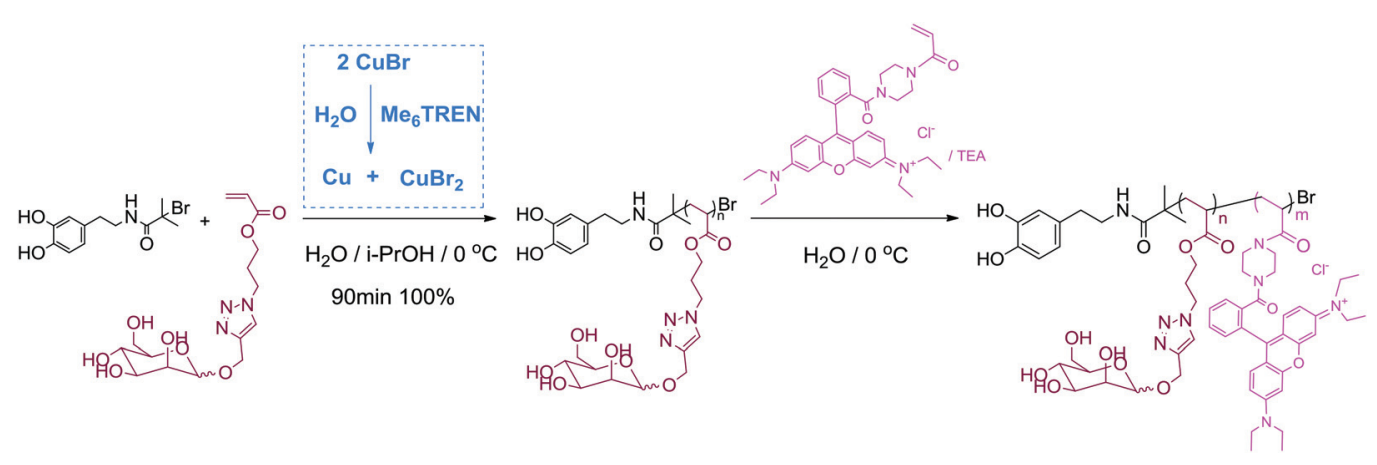

Scheme 1 Synthesis of dopamine-terminal fluorescent glycopolymers by aqueous SET-LRP.
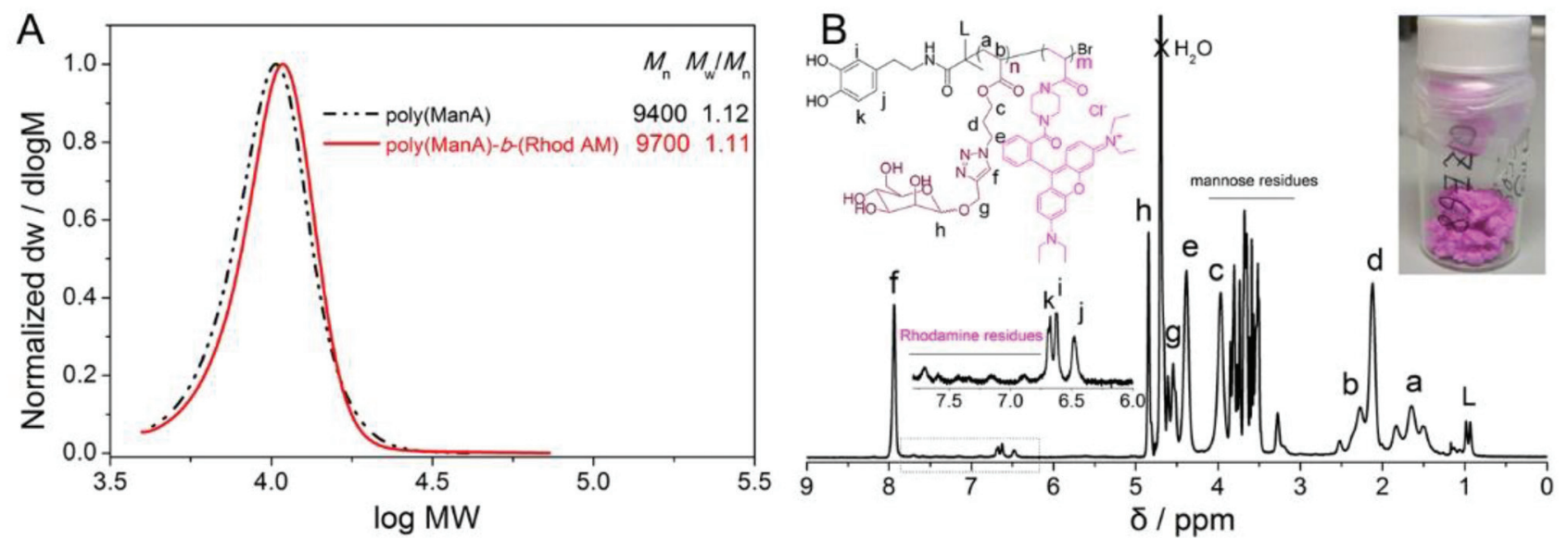

Fig. 2 Molecular weight distributions of dopamine-terminal poly(ManA) and poly(ManA)- $b$-(Rhod AM) by aqueous SET-LRP as measured by DMF SEC (A) and ${ }^{1} \mathrm{H}$ NMR spectrum of poly(ManA)- $b$-(Rhod AM) (B, the inset showed the pink fluffy product). 
groups and resulted in polymers with various functional groups, controlled MW and narrow MW distribution.

Preparation and characterization of polymer-coated fluorescent magnetic nanoparticles

The dopamine-terminal hydrophilic functional copolymers were used to fabricate water dispersible magnetic iron oxide nanoparticles by precipitation of the $\mathrm{Fe}(\mathrm{II})$ and $\mathrm{Fe}(\mathrm{III})$ salts by $\mathrm{NH}_{4} \mathrm{OH}$ in aqueous medium and subsequently coated with oleic acid. ${ }^{50}$ Nanoparticles prepared by this strategy were stabilized in water and TEM images showed irregularly shaped particles with varied diameter ranging from $\sim 5$ to $\sim 20 \mathrm{~nm}$, Fig. 3A. Excess amounts of dopamine-terminal copolymers were subsequently used for ligand exchange reaction with the
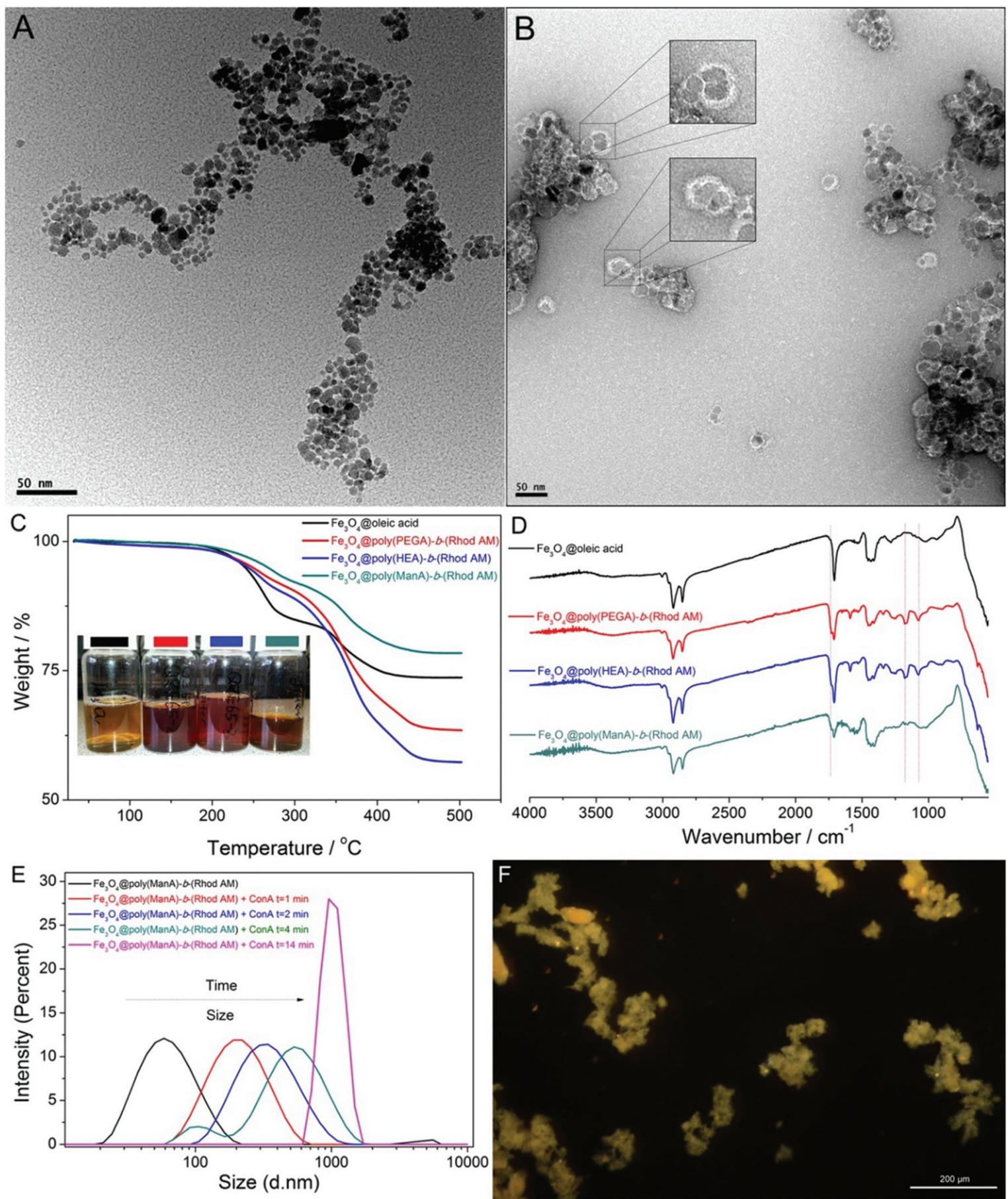

Fig. 3 TEM images of $\mathrm{Fe}_{3} \mathrm{O}_{4}$ aoleic acid (A) and $\mathrm{Fe}_{3} \mathrm{O}_{4}$ apoly(HEA)- $b$-(Rhod AM) (B); TGA (C, the inset showed the suspension of $\mathrm{Fe} \mathrm{O}_{3}$ particles) and FTIR (D) of $\mathrm{Fe}_{3} \mathrm{O}_{4}$ particles coated with oleic acid or dopamine-terminal fluorescent polymers; DLS (E) results and optical microscopy image (F) of $\mathrm{Fe}_{3} \mathrm{O}_{4}$ (apoly(ManA)- $b$-(Rhod AM) after addition of ConA. 


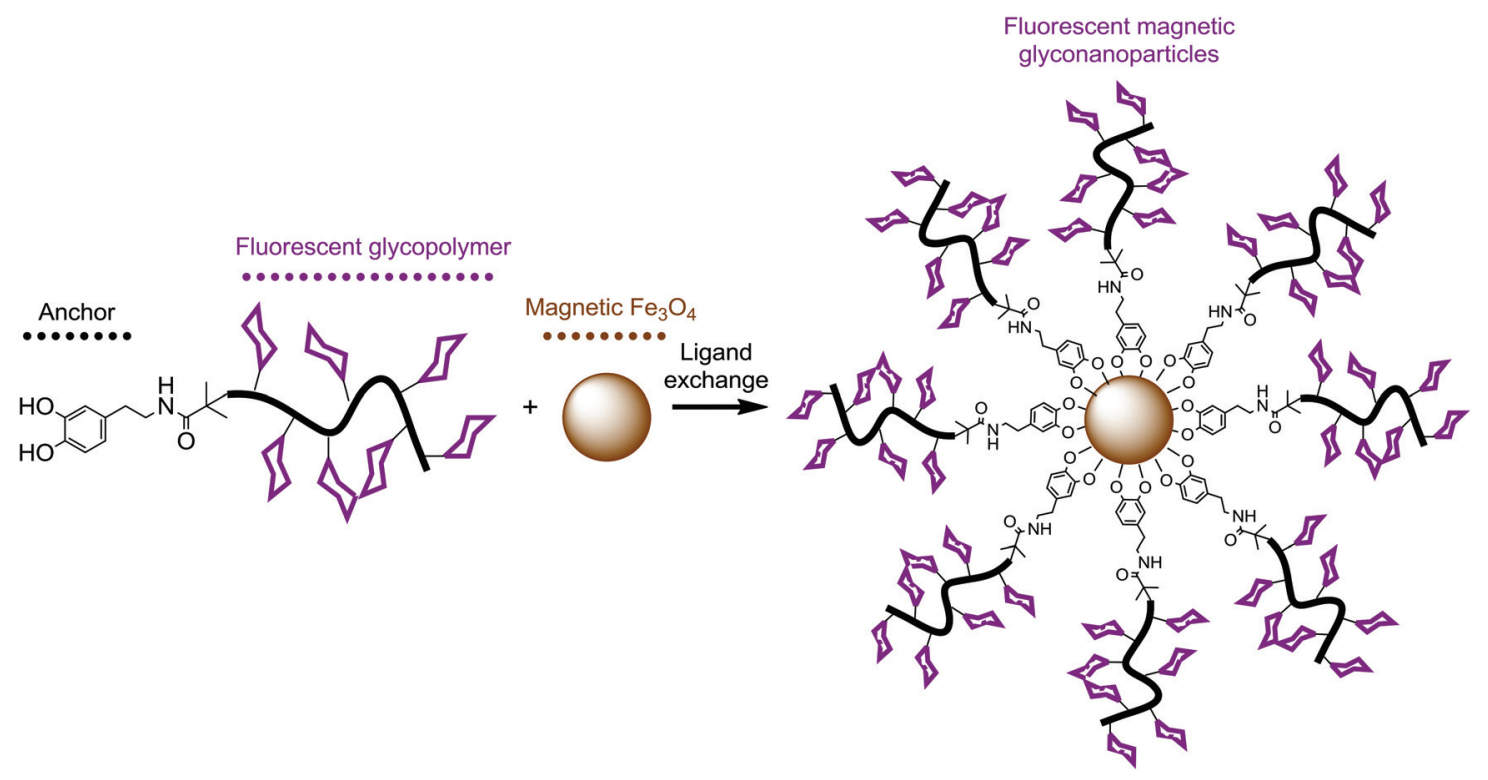

Scheme 2 Schematic illustration for the functionalization of magnetic iron oxide particles with dopamine-terminal fluorescent glycopolymers.

oleic acid coated iron oxide nanoparticles in water under nitrogen protection at $40^{\circ} \mathrm{C}$, Scheme 2 .

After the exchange reaction, the polymer coated nanoparticles were purified from the unbounded polymers via repeated separation and re-dispersion using high speed centrifuge and a strong magnet. Due to the presence of highly watersoluble and pink polymers on the surface of the nanoparticles after exchange with oleic acid, the polymer coated particles are readily dispersible in water without observed precipitation in weeks and the suspension showed a red colour rather than the light yellow colour of original iron oxide particles, Fig. 3C.

The staining technique improved the contrast of TEM images and revealed the presence of a thin and dense polymer layer $(5-10 \mathrm{~nm})$ on the surface of particles, which clearly proved that the bio-inspired anchor of dopamine-terminal polymer to transition metal oxide particles was efficient and successful, Fig. 3B. A part of the modified nanoparticles was separated and lyophilized as purple dried powders for further characterization using thermogravimetric analysis (TGA) and FTIR. Compared with the original oleic acid coated particles, TGA analysis of poly(PEGA 480$)-b$-(Rhod AM) and poly(HEA)- $b$ (Rhod AM) coated particles showed higher weight loss (Fig. 3C), probably due to the presence of much higher MW polymers on the surface. Interestingly, particles coated with relatively low DP and less amount of poly(ManA)-b-(Rhod AM) showed less weight loss during TGA test, which was similarly as one previous report. ${ }^{51}$ It was considered that the "grafting to" strategy generally had low efficiency in immobilizing polymers to the surface due to steric hindrance effect. Thus theoretically less polymers would be on the surface after ligand exchange reaction and the relatively low MW of poly(ManA)- $b$ (Rhod AM) further resulted in less weight loss on TGA. FTIR analysis (Fig. 3D) showed clear evidence of the polymer's presence on the particle surface by comparing the spectra of particles coated with oleic acid or block copolymers. The characteristic polymer IR absorbance peaks such as the carbonyl stretching at $\sim 1750 \mathrm{~cm}^{-1}$ and the $-\mathrm{CH}_{2}-\mathrm{CH}_{2}-\mathrm{O}$ stretching at $\sim 1000-1250 \mathrm{~cm}^{-1}$ were detected subsequent to the exchange reaction, indicating the success of functionalization.

In order to further prove the presence of carbohydrate on the surface of obtained glycoparticles, we added excess of concanavalin A (ConA) to the particle suspension to check the aggregation behavior caused by carbohydrate-protein interaction. Due to the recognition of lectin with mannose-rich polymers, the particles aggregated fast and the intensity average diameter measured by DLS increased from $\sim 50 \mathrm{~nm}$ to $\sim 200 \mathrm{~nm}$ after 1 minute and $\sim 600 \mathrm{~nm}$ after 4 minute (Fig. 3E). Just after addition of ConA for $14 \mathrm{~min}$, the presence of large irregularly shaped particles are already over the detect limit of our DLS system (shown as a narrow sharp peak, Fig. 3E) and could be even directly observed by optical microscopy (Fig. 3F).

In summary, the dopamine-terminal group anchor the copolymers to the surface of iron oxide is efficient and successful as revealed by varied characterization tools. The presence of these polymers increases the stability of particles in water and also endowed the particles different properties derived from the polymers.

\section{Cytotoxicity and cell uptake of fluorescent magnetic nanoparticles}

The cellular uptake of polymer coated nanoparticles by A549 cells (Tsinghua University, PRC) was investigated using confocal laser scanning microscope (CLSM) and the cell morphology was also observed to evaluate the cytotoxicity of nanoparticles. A549 cells were incubated in the presence of different concentrations of nanoparticles for up to 24 hours. After washing with PBS buffer to remove excess particles, the cells were first observed under bright field and the images 

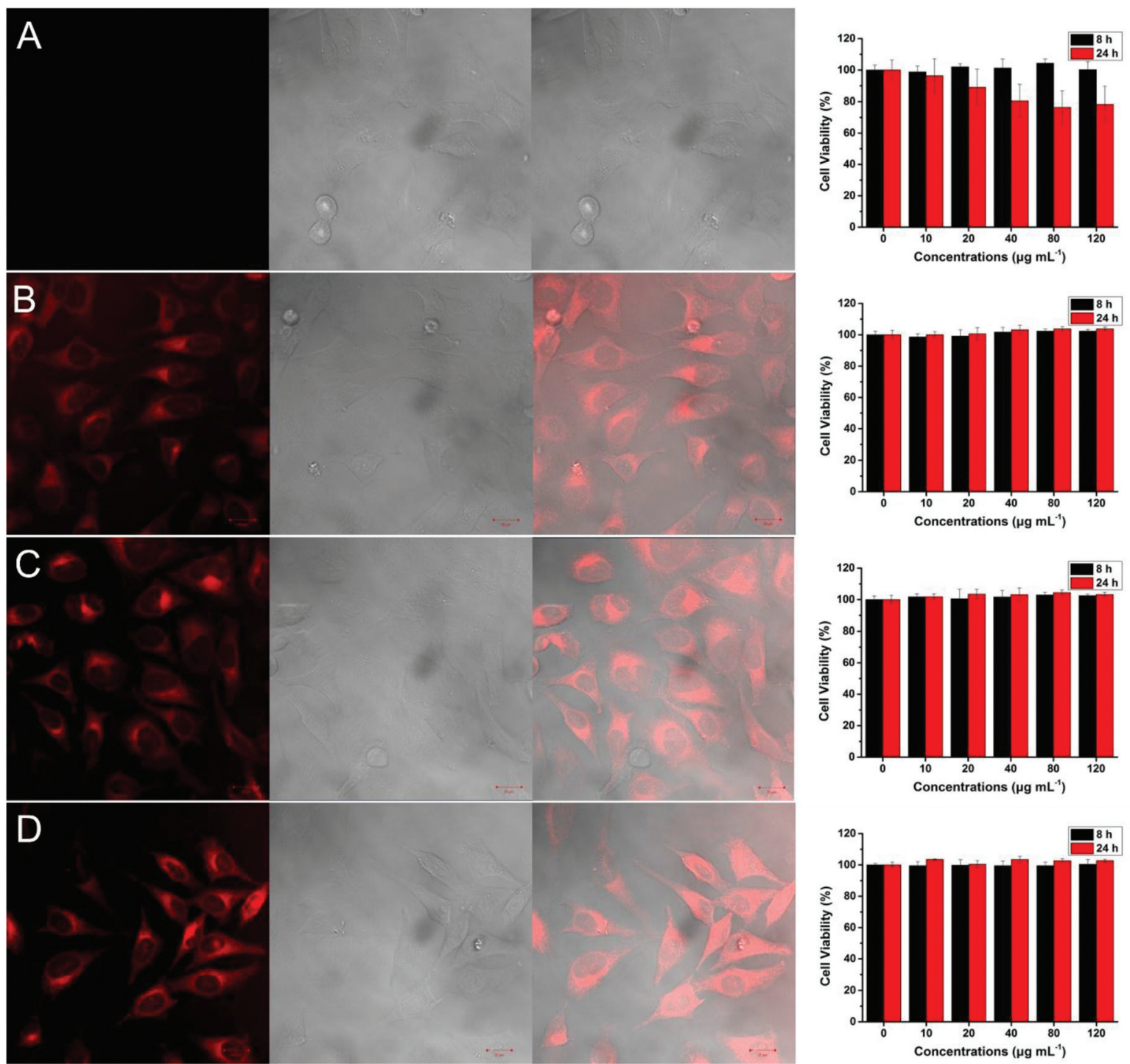

Fig. 4 Confocal laser scanning microscopy (CLSM) images and cell viability of $A 549$ cells with $\mathrm{Fe}_{3} \mathrm{O}_{4}$ @ooleic acid (A); $\mathrm{Fe}_{3} \mathrm{O}_{4}$ @poly(HEA)- $b$-(Rhod $\left.A M\right)$ (B); $\mathrm{Fe}_{3} \mathrm{O}_{4}$ (apoly $\left(\mathrm{PEGA}_{480}\right)$-b-(Rhod AM) (C); $\mathrm{Fe}_{3} \mathrm{O}_{4}$ (apoly(ManA)-b-(Rhod AM) (D). In each image the left: excited with $405 \mathrm{~nm}$ laser; the middle: bright field; the right: merged image of bright field and fluorescent field. The cell viability was determined by $\mathrm{CCK}_{-} 8$ assay. The concentration of Fe ${ }_{3} \mathrm{O}_{4}$ nanocomposites for CLSM is $100 \mu \mathrm{g} \mathrm{mL}$.

clearly demonstrated the maintained cell morphology under different concentrations of nanoparticles ranging from 10 to $120 \mu \mathrm{g} \mathrm{ml} \mathrm{m}^{-1}$, Fig. 4, which suggested that these particles have good biocompatibility. To further define the viability of A549 cells after being treated with different magnetic nanoparticles, a cell counting kit-8 (CCK-8) assay was utilized.

The cell viability decreased to around $80 \%$ when the concentration of $\mathrm{Fe}_{3} \mathrm{O}_{4} @$ @oleic acid was increased to $120 \mu \mathrm{g} \mathrm{ml}^{-1}$, which highlighted the adverse effect of $\mathrm{Fe}_{3} \mathrm{O}_{4}$ nanoparticles especially under relatively high concentrations, Fig. 4A. However, we did not observe any significant viability decrease when $\mathrm{Fe}_{3} \mathrm{O}_{4} @$ @poly(HEA)- $b$-(Rhod AM), $\mathrm{Fe}_{3} \mathrm{O}_{4} @$ @poly $\left(\mathrm{PEGA}_{480}\right)$ - $b$ (Rhod $\mathrm{AM}$ ) and $\mathrm{Fe}_{3} \mathrm{O}_{4} @$ @poly(ManA)-b-(Rhod AM) were present during the incubation, Fig. $4 \mathrm{~B}, \mathrm{C}$ and $\mathrm{D}$. Compared with the oleic acid, it is hypothesized that the presence of dense hydro- philic polymer brushes on the surface of $\mathrm{Fe}_{3} \mathrm{O}_{4}$ nanoparticles, which obviously had better water solubility, higher molecular weight, different functional groups and charge state, would theoretically lead to better coverage of the inorganic metal oxide core and better biocompatibility.

Previous research reported that the cell uptake of particles coated with mannose functionalized polymer tended to be mediated by the mannose receptors on the A549 cell surface and was faster and more significant than particle coated with PEG or glucose functionalized polymer. ${ }^{52}$ When excited with a $405 \mathrm{~nm}$ laser, the cells incubated with $\mathrm{Fe}_{3} \mathrm{O}_{4} @$ @oly(HEA)$b$-(Rhod $\mathrm{AM}), \quad \mathrm{Fe}_{3} \mathrm{O}_{4} @$ @poly $\left(\mathrm{PEGA}_{480}\right)-b$-(Rhod $\left.\mathrm{AM}\right)$ and $\mathrm{Fe}_{3} \mathrm{O}_{4} @$ @poly(ManA)-b-(Rhod AM) particles showed very strong fluorescence in the cytoplasm area (Fig. 4), while the cell nucleus area was much darker and the cells incubated with 
$\mathrm{Fe}_{3} \mathrm{O}_{4} @$ @oleic acid were completely dark under same excitation. These results further proved the immobilization of fluorescent polymers on the particle surface and the cells could take up these nanoparticles mainly into cytoplasm area. Although the cells were incubated with particles in same concentration and incubation time, the cells with $\mathrm{Fe}_{3} \mathrm{O}_{4} @$ @poly(ManA)- $b$-( $\mathrm{Rhod}$ $\mathrm{AM})$ proved to be no less or even more lighter than under CLSM images under visual observation (Fig. 4D). It needs to be emphasized that the $\mathrm{Fe}_{3} \mathrm{O}_{4}$ @poly(ManA)- $b$-(Rhod AM) showed least weight loss during TGA test (Fig. 3C) as least glycopolymer was used for surface modification compared with poly (HEA)- $b$-(Rhod AM) and poly $\left(\right.$ PEGA $\left._{480}\right)-b$-(Rhod AM) (ESI $\left.\dagger\right)$. These indicated that the cells may take more $\mathrm{Fe}_{3} \mathrm{O}_{4} @$ @oly (ManA)- $b$-(Rhod AM) than $\mathrm{Fe}_{3} \mathrm{O}_{4} @$ @poly(HEA)- $b$-(Rhod AM) and $\mathrm{Fe}_{3} \mathrm{O}_{4} @$ @poly $\left(\mathrm{PEGA}_{480}\right)-b$-(Rhod $\left.\mathrm{AM}\right)$ after same time, which also proved that the cellular uptake of mannose functionalized particles was faster than the others. Considering the excellent fluorescence and different cellular uptake behaviour, these particles may have potential application in biomedical imaging and targeting therapy.

\section{Conclusions}

In summary, well-defined hydrophilic polymers with terminal catechol groups have been successfully prepared by aqueous SET-LRP directly from an unprotected dopamine-functionalized initiator. The polymerizations showed excellent compatibility with the catechol groups as well as different functional monomers leading to final polymers with controlled MW and narrow MW distributions. Furthermore, the grafting of several fluorescent block copolymers to iron oxide particles led to dual-modal fluorescent nano materials as characterized by TEM, FTIR, TGA and DLS etc. Investigation of the polymercoated nanoparticles showed no significant cytotoxic effect, indicating its significant biocompatibility. Cellular-uptake of these nanoparticles by A549 cells was very efficient and suggested potential application in bioimaging, cell-glycopolymer interaction and RME process studies. The presented synthetic route opens up a novel approach for synthesis of welldefined catechol polymers as well as surface functionalization of various materials.

\section{Acknowledgements}

Q. Z. acknowledges the financial support from University of Warwick and the China Scholarship Council. D. M. H. was a Royal Society/Wolfson Fellow during this work.

\section{Notes and references}

1 X. Li and G. Chen, Polym. Chem., 2015, 6, 1417-1430.

2 W. Jiang, Y. S. KimBetty, J. T. Rutka and C. W. ChanWarren, Nat. Nanotechnol., 2008, 3, 145-150.
3 X. Chen, O. Ramström and M. Yan, Nano Res., 2014, 7, 1381-1403.

4 X. Li, M. Bao, Y. Weng, K. Yang, W. Zhang and G. Chen, J. Mater. Chem. B, 2014, 2, 5569-5575.

5 A. S. Zahr, C. A. Davis and M. V. Pishko, Langmuir, 2006, 22, 8178-8185.

6 Y. Goto, R. Matsuno, T. Konno, M. Takai and K. Ishihara, Biomacromolecules, 2008, 9, 3252-3257.

7 K. El-Boubbou, C. Gruden and X. Huang, J. Am. Chem. Soc., 2007, 129, 13392-13393.

8 C.-H. Lai, J. Hütter, C.-W. Hsu, H. Tanaka, S. VarelaAramburu, L. De Cola, B. Lepenies and P. H. Seeberger, Nano Lett., 2016, 16, 807-811.

9 C. Xu, K. Xu, H. Gu, R. Zheng, H. Liu, X. Zhang, Z. Guo and B. Xu, J. Am. Chem. Soc., 2004, 126, 9938-9939.

10 P. J. Endres, T. Paunesku, S. Vogt, T. J. Meade and G. E. Woloschak, J. Am. Chem. Soc., 2007, 129, 1576015761.

11 W. O. Yah, H. Xu, H. Soejima, W. Ma, Y. Lvov and A. Takahara, J. Am. Chem. Soc., 2012, 134, 12134-12137.

12 K. Cheng, S. Peng, C. Xu and S. Sun, J. Am. Chem. Soc., 2009, 131, 10637-10644.

13 M. Mazur, A. Barras, V. Kuncser, A. Galatanu, V. Zaitzev, K. V. Turcheniuk, P. Woisel, J. Lyskawa, W. Laure, A. Siriwardena, R. Boukherroub and S. Szunerits, Nanoscale, 2013, 5, 2692-2702.

14 J. Su, F. Chen, V. L. Cryns and P. B. Messersmith, J. Am. Chem. Soc., 2011, 133, 11850-11853.

15 J. Liu, W. Yang, H. M. Zareie, J. J. Gooding and T. P. Davis, Macromolecules, 2009, 42, 2931-2939.

16 C. Zobrist, J. Sobocinski, J. Lyskawa, D. Fournier, V. Miri, M. Traisnel, M. Jimenez and P. Woisel, Macromolecules, 2011, 44, 5883-5892.

17 W. Scarano, H. Lu and M. H. Stenzel, Chem. Commun., 2014, 50, 6390-6393.

18 Z. Jia, V. A. Bobrin, N. P. Truong, M. Gillard and M. J. Monteiro, J. Am. Chem. Soc., 2014, 136, 58245827.

19 N. Holten-Andersen, M. J. Harrington, H. Birkedal, B. P. Lee, P. B. Messersmith, K. Y. C. Lee and J. H. Waite, Proc. Natl. Acad. Sci. U. S. A., 2011, 108, 2651-2655.

20 A. Neves, L. M. Rossi, A. J. Bortoluzzi, B. Szpoganicz, C. Wiezbicki, E. Schwingel, W. Haase and S. Ostrovsky, Inorg. Chem., 2002, 41, 1788-1794.

21 G. Li, G. Cheng, H. Xue, S. Chen, F. Zhang and S. Jiang, Biomaterials, 2008, 29, 4592-4597.

22 C. Gao, G. Li, H. Xue, W. Yang, F. Zhang and S. Jiang, Biomaterials, 2010, 31, 1486-1492.

23 G. Li, H. Xue, C. Gao, F. Zhang and S. Jiang, Macromolecules, 2010, 43, 14-16.

24 M. Chanana, S. Jahn, R. Georgieva, J.-F. Lutz, H. Bäumler and D. Wang, Chem. Mater., 2009, 21, 1906-1914.

25 G. Rayner, University of Warwick, 2012.

26 Q. Zhang, P. Wilson, Z. Li, R. McHale, J. Godfrey, A. Anastasaki, C. Waldron and D. M. Haddleton, J. Am. Chem. Soc., 2013, 135, 7355-7363. 
27 G. R. Jones, Z. Li, A. Anastasaki, D. J. Lloyd, P. Wilson, Q. Zhang and D. M. Haddleton, Macromolecules, 2016, 49, 483-489.

28 S. Son and B. A. Lewis, J. Agric. Food Chem., 2002, 50, 468472.

29 C. Zhang, K. Li and J. Simonsen, J. Appl. Polym. Sci., 2003, 89, 1078-1084.

30 J. Yang, J. Keijsers, M. van Heek, A. Stuiver, M. A. Cohen Stuart and M. Kamperman, Polym. Chem., 2015, 6, 31213130 .

31 H. O. Ham, Z. Liu, K. H. A. Lau, H. Lee and P. B. Messersmith, Angew. Chem., Int. Ed., 2011, 50, 732736.

32 M. Álvarez-Paino, G. Marcelo, A. Muñoz-Bonilla and M. Fernández-García, Macromolecules, 2013, 46, 29512962.

33 V. Thavasi, R. P. A. Bettens and L. P. Leong, J. Phys. Chem. $A$, 2009, 113, 3068-3077.

34 K. Matyjaszewski and J. Xia, Chem. Rev., 2001, 101, 29212990.

35 V. Percec, A. V. Popov, E. Ramirez-Castillo, M. Monteiro, B. Barboiu, O. Weichold, A. D. Asandei and C. M. Mitchell, J. Am. Chem. Soc., 2002, 124, 4940-4941.

36 B. M. Rosen and V. Percec, Chem. Rev., 2009, 109, 50695119.

37 S. K. Jewrajka and B. M. Mandal, J. Polym. Sci., Part A: Polym. Chem., 2004, 42, 2483-2494.

38 S. K. Jewrajka and B. M. Mandal, Macromolecules, 2003, 36, 311-317.

39 D. A. Z. Wever, P. Raffa, F. Picchioni and A. A. Broekhuis, Macromolecules, 2012, 45, 4040-4045.
40 F. Alsubaie, A. Anastasaki, V. Nikolaou, A. Simula, G. Nurumbetov, P. Wilson, K. Kempe and D. M. Haddleton, Macromolecules, 2015, 48, 6421-6432.

41 A. Anastasaki, V. Nikolaou, G. Nurumbetov, P. Wilson, K. Kempe, J. F. Quinn, T. P. Davis, M. R. Whittaker and D. M. Haddleton, Chem. Rev., 2016, 116, 835-877.

42 V. Nikolaou, A. Simula, M. Droesbeke, N. Risangud, A. Anastasaki, K. Kempe, P. Wilson and D. M. Haddleton, Polym. Chem., 2016, 7, 2452-2456.

43 A. Anastasaki, V. Nikolaou and D. M. Haddleton, Polym. Chem., 2016, 7, 1002-1026.

44 N. V. Tsarevsky, T. Pintauer and K. Matyjaszewski, Macromolecules, 2004, 37, 9768-9778.

45 N. V. Tsarevsky and K. Matyjaszewski, Chem. Rev., 2007, 107, 2270-2299.

46 P. Y. Zavalii, M. G. Mys'kiv and V. S. Fundamenskii, Sov. Phys. Crystallogr., 1984, 29, 34-37.

47 K. B. Girma, V. Lorenz, S. Blaurock and F. T. Edelmann, Z. Anorg. Allg. Chem., 2008, 634, 267-273.

48 A. Limer and D. M. Haddleton, Macromolecules, 2006, 39, 1353-1358.

49 A. H. Soeriyadi, C. Boyer, F. Nyström, P. B. Zetterlund and M. R. Whittaker, J. Am. Chem. Soc., 2011, 133, 11128-11131.

50 D. Maity and D. C. Agrawal, J. Magn. Magn. Mater., 2007, 308, 46-55.

51 M. Arslan, T. N. Gevrek, J. Lyskawa, S. Szunerits, R. Boukherroub, R. Sanyal, P. Woisel and A. Sanyal, Macromolecules, 2014, 47, 5124-5134.

52 J. S. Basuki, L. Esser, H. T. T. Duong, Q. Zhang, P. Wilson, M. R. Whittaker, D. M. Haddleton, C. Boyer and T. P. Davis, Chem. Sci., 2014, 5, 715-726. 